\title{
A APLICAÇÃO DA FENOMENOLOGIA NOS ESTUDOS ORGANIZACIONAIS NO BRASIL
}

\author{
THE APPLICATION OF PHENOMENOLOGY \\ TO ORGANIZATIONAL STUDIES IN BRAZIL
}

Recebido em: 14/02/2012 Aprovado em: 17/04/2012 Avaliado pelo sistema double blind review Editora Científica: Manolita Correia Lima

\author{
ROGÉRIOZANON DASILVEIRA rsilveira@sefaz.es.gov.br \\ ANA CAROLINA GUERRA \\ CARLOS ALBERTO GONÇALVES \\ UNIVERSIDADE FEDERAL DE MINAS GERAIS
}

\section{RESUMO}

Este trabalho tem o objetivo de apresentar um entendimento a respeito de como o método fenomenológico vem sendo utilizado em pesquisas no campo dos estudos organizacionais. Para isso, foram analisadas pesquisas que utilizaram a fenomenologia, buscando compreender e descrever a sua utilização, as características semelhantes entre os temas estudados, as queixas e dificuldades relatadas pelos pesquisadores, os objetos de estudo e as técnicas de pesquisa, entre outros fatores. Os artigos selecionados são provenientes de trabalhos científicos utilizados na pesquisa feita por Silveira, Fischer e Olivier (20I0), que realizaram um mapeamento de artigos em Administração sobre a Fenomenologia e sobre sua aplicação como método de pesquisa. Para fins de atualização desta pesquisa, foram mapeados outros artigos publicados posteriormente nos mesmos eventos e periódicos. Pôde-se evidenciar que a abordagem fenomenológica ou o método fenomenológico tem alcance epistemológico consistente e significativo para aplicação ao estudo dos mais variados problemas no campo dos estudos organizacionais. Além disso, esse tipo de estudo buscou contribuir para a melhor assimilação do significado da fenomenologia, a compreensão de como se deu sua passagem do método filosófico para o método de pesquisa e, assim, entrever seu potencial de adoção em estudos organizacionais.

Palavras-chave: fenomenologia; metodologia; estudos organizacionais.

\begin{abstract}
This paper aims to understand how the phenomenological method has been used for research in the field of organizational studies. Studies using phenomenology were thus analyzed in order to understand: their use, the similarities among the subjects studied, the problems and difficulties reported by the investigators, the research subjects and techniques, among other factors. The selected articles came from scientific papers used in the research study by Silveira, Fischer and Olivier (2010), who mapped out the scientific articles, within the field of Business Administration, on phenomenology and its application as a research method. In order to update this study, other articles subsequently published in the same events and periodicals were also mapped. It was observed that the phenomenological approach or method has a consistent and significant epistemological potential for application in studying a variety of problems within the field of organizational studies. Moreover, these kinds of studies can contribute to further assimilation of the meaning of phenomenology, to understanding its transition from the philosophical method to the research method and, thus, to perceiving their potential for use in organizational studies.

Keywords: phenomenology; methodology; organizational studies.
\end{abstract}




\section{INTRODUÇÃO}

O objetivo deste artigo é apresentar um entendimento de como a fenomenologia ou o método fenomenológico vem sendo utilizado em pesquisas, no campo dos estudos organizacionais, no Brasil. A fenomenologia, para Husserl (200I), é uma "doutrina” que sustenta que o ser humano, por meio de seu intelecto, intui certeza imediata e absoluta sobre algo que se deixa perceber ou que entra em seu campo sensorial. A passagem da fenomenologia como filosofia para um método fenomenológico de pesquisa tem sido reivindicada por muitos pesquisadores, mas, em grande parte dos estudos em que ela é utilizada, seja como base para obtenção, seja como interpretação de dados, ou melhor, de fenômenos, como será visto melhor adiante, essa passagem não fica muito clara. Ademais, a continuidade das ideias de Husserl (200I) derivaram de ramificações filosóficas variadas, implicando complexidades maiores. O próprio Husserl (200I) considerava que suas ideias estavam inacabadas e se autointitulava um eterno iniciante em filosofia (MOREIRA, 2002).

A dificuldade em aplicar a fenomenologia como método de pesquisa passa ainda por outras barreiras. Como qualquer outro movimento filosófico, compreender a fenomenologia é tarefa árdua e exige muita dedicação em seu entendimento e em sua posterior utilização. Giorgi (1985) atribui a dificuldade do pensamento fenomenológico a três questões principais: (I) a de ir contra a tendência natural da consciência de dirigir-se às coisas em vez de a seus processos; (2) à evolução que o trabalho de Edmund Husserl, fundador da fenomenologia, teve durante toda a sua vida, além das alterações que se seguiram e ainda continuam; e (3) à incerteza quanto à consistência das interpretações dos discípulos de Husserl.

Quando aplicado na filosofia, o método fenomenológico apresenta-se mais como doutrina do que como conjunto de procedimentos de trabalho de pesquisa, mas, seu sentido acaba também se ampliando, variando entre uma e outra interpretação. $\mathbf{O}$ método fenomenológico, no âmbito da filosofia, significa método de estudo da fenomenologia. Outra questão que torna mais complexa a ideia de fenomenologia reside no fato de vários 
pensadores terem desenvolvido ideias fenomenológicas, como Heidegger, Merleau - Ponty, Sartre, Gabriel Marcel, Paul Ricoeur e outros, além do próprio Edmund Husserl, como explica Moreira (2002, p. 6), lembrando Herbert Spieglberg, historiador da fenomenologia que desenvolveu "a mais completa abordagem sobre o método fenomenológico".

Os métodos de pesquisa mais tradicionais são oriundos da ciência social, como a antropologia, a psicologia e a filosofia. A fenomenologia é considerada um dos movimentos filosóficos mais importantes do século xx e, desde seu início, teve associação estreita com a psicologia, recém criada, que acabou servindo de meio para disseminação do método fenomenológico para outras áreas no campo das ciências sociais. Em relação à sua utilização na prática, como método de investigação, é possível afirmar que o método fenomenológico é relativamente inexplorado, basicamente devido à sua complexa compreensão, especialmente por quem não é da área da filosofia, como assinala Moreira (2002).

Esse breve panorama fornece uma dimensão tanto da dificuldade de compreensão, quanto de aplicação do método fenomenológico nas pesquisas sociais, e possibilita imaginar os percalços no caminho da transposição do método fenomenológico para método de pesquisa no campo dos estudos organizacionais. É nesse contexto que este artigo se insere, quando reúne pesquisas que utilizaram o método fenomenológico e busca compreender como se deu sua utilização, as características semelhantes dos temas estudados, os problemas, as dificuldades relatadas pelos pesquisadores, os objetos de estudo e técnicas de pesquisa, entre outros elementos. Esse tipo de estudo pode contribuir para melhor assimilação do significado da fenomenologia; para ajudar a entender como se deu sua passagem do método filosófico para o método de pesquisa; e entrever seu potencial para utilização nos estudos organizacionais. 


\section{OS ESTUDOS ORGANIZACIONAIS NO BRASIL: ENTRE A SUBJETIVIDADE E A OBJETIVIDADE}

Assim como a complexidade que marca a trajetória da fenomenologia, a própria trajetória de Husserl (200I), em seus estudos, foi marcada por idas, vindas, fracassos e frustrações. Suas cartas mostram "que ele sofria de longos períodos de desespero filosófico e de depressão (...) levando-o à doença, intercalados com curtos períodos de grande criatividade e furiosa composição", assinala Moran (2000, p. 62). O caminho da fenomenologia na pesquisa qualitativa também não foi menos intricado. Como observa Sampaio (2000, p. I6), "em meio ao pensamento administrativo, a noção de ciência mais difundida filia-se às escolas derivadas do empirismo", que surge com a obra de Francis Bacon, Novum organum, que propunha que "o estudo se voltasse à análise da natureza, cujos resultados pudessem permitir acumulação sistemática de conhecimento" (BACON, 1988). A ideia desenvolvida por Francis Bacon, ainda por volta do século xIv, continha a proposta de utilização do método indutivo como caminho para se atingir esse objetivo, que se daria por meio de experiências escrituradas, compreendendo a observação sistemática e a realização de experimentos.

Esse breve resumo dá uma dimensão de quão contrapostos estão, em dimensões ontológicas e epistemológicas, a fenomenologia e o empirismo, respectivamente situados nos campos paradigmáticos subjetividade $\mathrm{e}$ objetividade. O debate em torno da dicotomia subjetividade e objetividade ganhou peso nos estudos organizacionais após a publicação da obra de Burrell e Morgan (1979), "Sociological paradigms and organizational analisys", que definiu quatro paradigmas em cujas bases seria possível, segundo seus autores, classificar teorias e metodologias de pesquisa em Administração. Os quatro paradigmas são: humanismo radical, interpretativismo, estruturalismo radical e funcionalismo.

No Brasil, os estudos fundamentados no paradigma interpretativista têm crescido bastante, especialmente a partir das décadas de 1980 e 1990, mas ainda podem ser considerados exceção em vista da predominância de estudos funcionalistas. Porém, ainda que prevaleça a dominância 
positivista e funcionalista, os estudos organizacionais são caracterizados pela utilização de perspectivas teóricas e metodológicas variadas, e foi numa tentativa de trazer esclarecimento a essa diversidade que Burrell e Morgan (1979) trabalharam o mapeamento dessas teorias. Os professores basearam-se no fato de que cientistas sociais estudam seus temas por meio de pressupostos que dizem respeito à natureza do mundo social e à forma pelo qual esses pressupostos podem ser investigados, pensavam.

O primeiro desses pressupostos está associado à ontologia, que coloca aos pesquisadores a questão de observarem se a realidade social a ser estudada é externa ao ser humano ou se é fruto de sua consciência. Essa questão dá uma ideia da dimensão que separa os dois pontos de vista, objetivo e subjetivo, ideia sobre a qual se debruçam inúmeros estudiosos. Esse primeiro pressuposto se desdobrará ainda em outros três. Um no nível epistemológico, que coloca frente a frente a questão sobre como compreender o mundo e transmitir esse conhecimento, situando de um lado a defesa de que o conhecimento é algo concreto, objetivo, real, e possível de ser transmitido objetivamente; e de outro a visão de que o conhecimento é algo subjetivo ou até mesmo transcendental, que está fundamentado no sentido e na experiência pessoal.

O outro desdobramento ocorre no plano de compreensão da natureza humana, ou seja, em pensar num ser humano forjado com base no meio social em que vive, ou admitir o ser humano como sujeito, construindo o seu ambiente social (BERGER; LUKHMANN, 2003). Elaboradas as dualidades nas dimensões do ontológico, do epistemológico e na forma de compreensão da natureza humana, é possível pensar sobre os desdobramentos que acarretarão nos métodos de pesquisa a serem utilizados nos estudos organizacionais. Cada um desses três conjuntos de pressupostos, que se dicotomizam, acarretam consequências substanciais nas formas de pesquisar e obter conhecimento no mundo social. Ou seja, metodologias de pesquisa diferentes originam-se de diferentes ontologias, epistemologias e modos de compreensão da natureza humana.

Essas reflexões originadas das ideias de Burrell e Morgan (1979) possibilitam entender porque o debate ontológico situa em campos 
opostos a visão nominalista e a visão realista. Como explicam Berger e Lukhmann (2003), o realista compreende a existência do mundo social existente independentemente da uma percepção desse mundo por parte do ser humano. Para o nominalista, tudo o que existe em termos de conceitos, títulos ou nomes são meras criações artificiais, que têm o objetivo apenas de dar sentido, descrever e interagir com o mundo externo. O debate epistemológico, por sua vez, confronta as visões positivistas e antipositivistas. Berger e Lukhmann (2003) utilizam o termo positivista para caracterizar epistemologias, que buscam explicar a realidade social por meio de regularidades e de relações de causa e efeito entre elementos. $\mathrm{Na}$ visão antipositivista, porém, o mundo social somente pode ser entendido com base no ponto de vista das pessoas, ou seja, da perspectiva do sujeito envolvido naquilo que está sendo estudado.

As ideias de Burrell e Morgan (1979) se desdobram ainda em outros aspectos, como, por exemplo, a inclusão da dualidade ordem e conflito nos paradigmas sociológicos, situando, de um lado, pensamentos que pregam a mudança social, inspirados principalmente em interpretações das ideias de Karl Marx. De outro lado, estão pensamentos que defendem a ideia da manutenção e da ordem, sintetizada no termo regulação (funcionalismo). Em síntese, a dualidade ordem e conflito é acrescentada por Burrell e Morgan (1979) à dualidade objetividade e subjetividade, para darem origem aos quatro paradigmas sociológicos: humanismo radical e interpretativismo, no lado da subjetividade; e estruturalismo radical e regulação, no lado da objetividade, como representa o Quadro I. No humanismo radical e no estruturalismo radical estão contempladas as ideias e teorias sociais que pregam a mudança da ordem social; e nos paradigmas do interpretativismo e da regulação estão ideias a favor da manutenção da ordem estabelecida.

Quadro 1 Os Quatro Paradigmas Sociológicos de Burrell e Morgan (1979)

\begin{tabular}{|l|l|}
\hline Humanismo Radical & Estruturalismo Radical \\
\hline Interpretativismo & Regulação / Funcionalismo \\
\hline
\end{tabular}


Exemplificando, as "regras do método sociológico", desenvolvidas por Durkheim (1972) para o estudo do "fato social", objeto de estudo da sociologia, podem ser situadas no quadrante da regulação (funcionalismo). O fato social é construído e objetivado para ser estudado por meio de recursos utilizados para o estudo do mundo natural, com o uso da matemática, por exemplo. Do outro lado, no quadrante do interpretativismo, e retomando a temática desta pesquisa, estaria a fenomenologia.

\section{CONCEITOS BÁSICOS DA FENOMENOLOGIA DESENVOLVIDOS POR EDMUND HUSSERL}

Como já foi dito, para Husserl, a fenomenologia é uma doutrina que defende que o intelecto intui uma certeza sobre a essência das coisas, de forma imediata e absoluta. Diz Husserl em sua obra Investigações Lógicas, que Fenomenologia é

uma zona neutral de investigação, onde as ciências têm raízes. [...] A fenomenologia nunca se orienta pelos fatos (externos ou internos), mas pela realidade da consciência, isto é, para aquilo que se manifesta imediatamente na consciência, alcançada por uma intuição, antes de toda reflexão ou juízo: as essências ideais (fenômenos) (RIBEIRO JR., I99I, p. 24-25).

A fenomenologia era entendida por Husserl como uma forma nova, porém, fundamental de fazer filosofia. Todos os ramos da filosofia têm fundamentos na fenomenologia e por meio exclusivamente de seu desenvolvimento obtém-se suas próprias forças: "a filosofia é possível como uma ciência definitivamente rigorosa somente por meio da Fenomenologia pura" (MOREIRA, 2002, p. 62). A fenomenologia surge com a obra Investigações Lógicas, de Edmund Husserl (1859 - 1938), para quem a fenomenologia era uma maneira nova de fazer filosofia, que entrando em contato diretamente com as "coisas próprias" dava destaque à experiência de vida, deixando de lado especulações metafísicas e abstratas.

A definição dada no Dicionário Aurélio para o termo fenômeno tem consonância com o conceito de Edmund Husserl, definição interpretada por Moreira (2002, p. 63), de que fenômeno "inclui todas as formas pelas 
quais as coisas são dadas à consciência", e (...) "todas as formas de estar consciente de algo quer dizer que ele inclui também qualquer espécie de sentimento, desejo e vontade, com seu comportamento imanente". Mas o termo fenômeno é utilizado de forma bastante abrangente, por exemplo, pode indicar alteração de um corpo por ação química ou física, como a ferrugem, o corte da árvore, a queda da maçã, o choque de corpos, a digestão, etc. Moreira (2002) também explica que o termo fenômeno pode ter sentidos como quando se diz que Pelé foi um fenômeno, ou quando um movimento social de massa é um fenômeno, porém

Etimologicamente, Fenomenologia é o estudo ou a ciência do fenômeno, sendo que por fenômeno, em seu sentido mais genérico, entende-se o que aparece, que se manifesta ou se revela por si mesmo. O conceito de fenômeno representa, a nosso ver, a primeira grande dificuldade no estudo da Fenomenologia (MOREIRA, 2002, p. 63).

Essa ideia tem associação com a de percepção pessoal da realidade. Por exemplo, a cadeira diante de nós não é um fenômeno. Fenômeno seria a aparência que percebemos da cadeira, logo no momento em que a vemos. $\mathrm{O}$ vento seria um fenômeno, ou melhor, a percepção que temos dele quando ele bate no corpo. O fenômeno seria então a informação que se apreende na consciência. Para a Fenomenologia, não interessam a cadeira e o vento, mas sim a forma como são percebidos na consciência. "O que aparece na consciência é o fenômeno", com o significado de "trazer à luz, colocar sob iluminação, mostrar-se a si mesmo em si mesmo, a totalidade do que se mostra diante de nós" (MOUSTAKAS, 1994, p. 26).

Essa aparência de algo na consciência, entendida como fenômeno, referese às coisas físicas, mas também à aparência de algo desejado, temido, intuído ou imaginado. O fenômeno inclui as formas de estar consciente de algo, o que inclui também pensamentos, vontades, desejos. Mas o fenômeno tem natureza própria e não é simples representação do objeto. A investigação com base na fenomenologia enfatiza a experiência que se vive no mundo da vida, que é "o mundo do cotidiano em que vivemos, agimos, fazemos projetos, entre outros, o da ciência, em que somos felizes ou infelizes" (DARTigues, 1992, p. 79). Por isso, o método fenomenológico é aplicado 
quando se pretende destacar a experiência de vida das pessoas. Lyotard (1967) explica que a fenomenologia se refere ao estudo dos fenômenos, ou seja, daquilo que é dado ou aparece à consciência.

Trata-se de explorar este dado, a própria coisa que se percebe, em que se pensa, de que se fala, evitando forjar hipóteses, tanto sobre o laço que une o fenômeno com o ser de que é fenômeno, como sobre o laço que o une com o Eu para quem é fenômeno (LYOTARD, 1967, p. 9).

A fenomenologia é compreendida por Forghieri (1984) não como um conjunto de ensinamentos, mas como um método que aspira chegar ao fenômeno por visão categorial; que tem o objetivo de captar a essência do fenômeno. A autora enfatiza a distinção que Husserl (1967) faz sobre dois tipos de conhecimento: o categorial e o objetivo. O primeiro se dá por meio da percepção categorial; e o segundo se dá por meio da percepção objetiva. A percepção objetiva seria fruto da ação reflexiva do sujeito, por meio da qual busca estabelecer uma distância em relação ao objeto e examiná-lo em seus elementos, características e funções. A percepção objetiva é própria das ciências da natureza.

A percepção categorial é imediata, espontânea, pré-reflexiva, própria da vida cotidiana, do vivenciar imediato - nela não há separação entre consciência e objeto e este é captado na sua totalidade por intuição. Ela assimila uma realidade básica, primordial, total, anterior à reflexão - é a percepção própria das ciências do homem (FORGHIERI, 1984, P. I5).

Moreira (2002) lembra que Merleau-Ponty (1999) considerava estranho que ainda em I9I4 fosse preciso explicar o que é fenomenologia, depois de meio século dos primeiros trabalhos de Husserl, mas algo que segundo ele ainda estava longe de ser resolvido. Merleau-Ponty (1999) procurou explicar fenomenologia como o estudo das essências: os problemas da fenomenologia resumem-se na definição das essências, como a essência da percepção e a essência da consciência, o que vai ao encontro da ideia de Husserl, de que as raízes do conhecimento deviam ser encontradas nas coisas, nos fenômenos, no senso costumeiro. Segundo Moreira (2002), Husserl acreditava que tais raízes estavam a fundo no sujeito, ou seja, na consciência do sujeito que as conhece, e para quem os fenômenos apareciam em algo que Husserl veio 
a chamar mais tarde de subjetividade transcendental. A volta ao objeto foi suplementada por um retorno ao sujeito.

A fenomenologia contém outros conceitos importantes para sua compreensão, assim com também é importante compreender bem alguns conceitos que são fundamentais no âmbito da fenomenologia. $\mathrm{O}$ primeiro deles refere-se ao conceito de essência, ligado à defesa de que a Fenomenologia deve ser concebida como uma ciência de rigor, uma ciência pura, uma ciência das essências. Moreira (2002, p. 84) explica que as essências correspondem a unidades de sentido observadas por indivíduos diferentes nos mesmos atos, ou pelo mesmo indivíduo em diferentes atos. As essências são as unidades básicas de entendimento comum de qualquer fenômeno. "Quando um fato se nos apresenta à consciência, juntamente com ele captamos uma essência” (MOREIRA, 2002, p. 84). E com isso,

A Fenomenologia seria uma ciência que partiria “do zero", sem pressuposições. O foco da Fenomenologia está no que é dado pela intuição, pois "Husserl segue o princípio dos princípios, segundo o qual o conhecimento dado originalmente pela intuição é conhecimento verdadeiro e deve ser aceito como se apresenta (MOREIRA, 2002, p. 83).

Outro conceito fundamental é o de intencionalidade. A ideia de intencionalidade está associada à ideia de que a consciência está dirigida a algo ou está consciente de um objeto. Nesse conceito aportam outros dois: o de imanente e o de transcendente. $\mathrm{O}$ imanente corresponde ao que se vê, o lado de um dado, por exemplo, ou à parte da frente de uma árvore. Já o transcendente é a objetivação pessoal da árvore. A transformação do imanente em transcendente, ou seja, a transformação da simples imagem do objeto em significação do objeto é feita por meio do procedimento que é chamado de análise intencional. Assim,

Dizer que a consciência é intencional significa dizer que toda consciência é consciência de algo. A consciência não é uma substância, mas uma atividade constituída por atos (percepção, imaginação, volição, paixão, etc.), com os quais visa algo (MOREIRA, 2002, p. 85).

Moreira (2002, p. 85) expressa que se chega assim à explicação essencial para o entendimento do conceito de fenômeno: "É a consciência intencional que 
faz o mundo aparecer como fenômeno, como significação, pelo fato de ser um cogitatum intencionado pelo sujeito", o que remete ao exemplo dado anteriormente. Analogamente, a cadeira não é um fenômeno. A cadeira é o imanente. A objetivação ou a percepção da cadeira na consciência, feita na passagem do imanente para o transcendente, é que é o fenômeno. A consciência não corresponde a algo, mas ao que lhe dá sentido. Husserl trata também de dois conceitos importantes para a fenomenologia, que são os de mundo natural e atitude natural. A atitude natural está associada à concepção de senso comum:

$\mathrm{Na}$ atitude natural, a consciência (ingênua) vê os objetos como sendo exteriores e reais. As ciências da atitude natural ou dogmática são concebidas sob o domínio da atitude natural e partem de uma objetividade dada, sem questioná-la. O oposto é a atitude filosófica ou atitude fenomenológica, segunda a qual o mundo é simplesmente o que ele é para a consciência, ou seja, fenômeno (MOREIRA, 2002, p. 85).

$\mathrm{Na}$ atitude fenomenológica não está a preocupação com aquilo que seja real, pois o objetivo da fenomenologia é compreender vivências intencionais da consciência, para então perceber o sentido dos fenômenos. Outro conceito é o de evidência apodítica, que pode ser entendido como um saber certo e indubitável. O conceito de evidência apodítica está no fundamento da defesa de que para a construção de uma filosofia como ciência de rigor, ciência pura, somente podem ser admitidos como validados juízos advindos da evidência apodítica.

Significa o aparecimento do que verdadeiramente é, e é por isso tão manifesto que exclui a possibilidade de dúvida e de erro. A evidência é um critério de verdade e de certeza. Para Husserl, vai haver evidência sempre que haja uma adequação completa entre o intencionado e o dado, quando se dê um "preenchimento da intenção", isto é, a intenção receba a absoluta plenitude do conteúdo, a plenitude do próprio objeto” [...] Sem a evidência, não será possível falar de fundamentação radical. No entanto, não é qualquer evidência que é satisfatória: apenas a evidência apodítica, com ausência total de dúvida (MOREIRA, 2002, p. 86).

Até aqui, foram abordados alguns dos principais conceitos que compõem 
a fenomenologia, como o de fenômeno, essência, intencionalidade, imanente, transcendente, evidência apodítica, conhecimento categorial e objetivo, mas é possível ao menos tangenciar um dos conceitos mais complexos e controversos para a noção da fenomenologia de Edmund Husserl: o conceito de redução fenomenológica. O conceito foi introduzido, segundo Moran (2000), face à preocupação de Husserl com a compreensão de intuição. Mas desde sua origem, o conceito de redução tem sido um tanto confuso e indeterminado.

Essa breve incursão nas origens, nos conceitos e em algumas complexidades que acompanham a Fenomenologia ajudam na noção de como se deu a passagem de um método filosófico para um método de pesquisa, ou seja, da fenomenologia e do método fenomenológico para o método fenomenológico de pesquisa. Nesse contexto, percebe-se que a fenomenologia pode entrar no mundo do outro e, assim, ser útil para o estudo em Administração. Assim como os conceitos envolvidos na fenomenologia, o próprio conceito de método fenomenológico não tem um significado ou uma utilização muito rígida. É que por método podese entender um procedimento de investigação organizado, que resulte na obtenção de resultados válidos. Em seu primeiro sentido, o método fenomenológico não está associado a procedimento, mas sim a um conjunto de princípios que fundamentam a fenomenologia. É nesse contexto que se insere este ensaio, que também envolve a questão de compreender até que ponto o método fenomenológico situado no âmbito da filosofia reflete o método fenomenológico de pesquisa transportado para outras disciplinas e para o campo dos estudos organizacionais. 


\section{ESCLARECIMENTOS SOBRE O MÉTODO DE PESQUISA UTILIZADO}

Este estudo pode ser caracterizado como pesquisa bibliográfica (GIL, 2002), pois foi desenvolvido com base em material já elaborado, especialmente livros e artigos científicos. O referencial teórico principal que sustenta este trabalho são as ideias sobre fenomenologia desenvolvidas por Edmund Husserl (HUSSERL, 1967, 200I). Os artigos selecionados para servirem como unidades de análises são provenientes de trabalhos científicos utilizados na pesquisa feita por Silveira, Fischer e Olivier (2010), que mapearam artigos científicos em Administração sobre a Fenomenologia e sobre sua aplicação como método de pesquisa nos estudos organizacionais.

Esses autores encontraram 43 artigos publicados nos principais periódicos e eventos, no período de 1997 a 2008, no âmbito da Associação Nacional de Pós-Graduação e Pesquisa em Administração. O critério utilizado por esses pesquisadores para escolha dos periódicos e revistas pesquisados foi selecionar os que obtiveram conceito "A" dado pela Coordenação de Aperfeiçoamento de Pessoal de Nível Superior (CAPES) no ano de 2008. Para fins de atualização desta pesquisa, foram mapeados outros artigos nos mesmos periódicos e eventos publicados posteriormente nesses mesmos periódicos e revistas. Do total dos artigos revistos, foram selecionados os trabalhos considerados pelos autores deste artigo como os mais adaptados ao objetivo proposto, chegando-se à quantidade de dez artigos.

As revistas pesquisadas foram: Organizações e Sociedade - O\&S, da Universidade Federal da Bahia; Revista de Administração Contemporânea - RAC; Revista de Administração da Universidade de São Paulo - RAusP; Revista de Administração de Empresas - RAE, da Fundação Getulio Vargas/ SP; Revista de Administração Pública - RAP, da Fundação Getulio Vargas/RJ; Revista Eletrônica de Administração - READ, da Universidade Federal do Rio Grande do Sul; e Cadernos ebape, periódico on-line sobre Administração Pública e de Empresas, da Escola Brasileira de Administração Pública e de Empresas da Fundação Getulio Vargas. Em relação aos eventos, foram pesquisados o Encontro da Associação Nacional de Pós-graduação e Pesquisa em Administração - ENANPAD; Encontro de Marketing da ANPAD 
- EMA; Encontro de Estudos Organizacionais da ANPAD - Êneo; Encontro de Administração Pública e Governança da ANPAD - ENAPG; e Simpósios ENANPAD.

Nesta pesquisa, os dez artigos escolhidos foram examinados buscando principalmente compreender como se deu a aplicação da fenomenologia ou do método fenomenológico nesses trabalhos. Ou melhor, que abordagem fenomenológica foi adotada ou assumida pelos autores. Em resumo, foram obedecidas as seguintes etapas até se chegar às unidades de análise: escolha de periódicos e revistas em Administração para busca de artigos relacionados à fenomenologia e ao método fenomenológico; levantamento dos artigos; leitura atenciosa de cada artigo; seleção dos dez artigos que mais se adequaram ao objetivo desta pesquisa; releitura dos artigos selecionados, examinando e extraindo deles os elementos principais, como, objetivo do artigo, problema de pesquisa, objeto de estudo, aplicação da fenomenologia ou do método fenomenológico, técnicas e instrumentos para obtenção de dados, principais interpretações realizadas, dificuldades relatadas e resultados alcançados.

Em consonância com o referencial teórico utilizado, a fenomenologia e o método fenomenológico, os autores deste artigo buscaram aplicar em suas interpretações conceitos básicos que formam a compreensão dessa abordagem, principalmente os de fenômeno e essência. Isso foi feito tentando captar a impressão a respeito dos conteúdos dos artigos analisados, e transpondo-os diretamente para o papel, a fim de não se perder o "essencial", intuitivo, captado pelo intelecto do "fenômeno" pesquisado.

\section{O USO DA FENOMENOLOGIA E DO MÉTODO FENOMENOLÓGICO EM PESQUISAS SOBRE ORGANIZAÇÕES REALIZADAS NO BRASIL}

No campo dos estudos organizacionais, a aplicação da Fenomenologia e do Método Fenomenológico tem sido caracterizada pela diversidade de temas, setores, objetos, problemas e assuntos abordados. É possível observar ainda a diversidade de abordagens fenomenológicas utilizadas, assim como interpretações diferentes ou criativas para as abordagens escolhidas. No tocante especificamente à aplicação prática dos conceitos que 
envolvem a fenomenologia, as interpretações a respeito são mais difíceis de serem construídas, mas é possível observar que os pesquisadores em Administração estão ainda tateando esse campo, devido principalmente à pouca quantidade de trabalhos científicos publicados que utilizam o método fenomenológico.

Bauer e Mesquita (2008, p. I), num premiado trabalho, estudaram o tema da agroecologia e buscaram compreender como a identidade e a realidade social são construídas e reconstruídas socialmente. Utilizaram o que chamaram de abordagem fenomenológica para investigar como se dá a ruptura com a realidade convencional e a transição para a agroecologia, lançando mão do aporte teórico-metodológico da fenomenologia. Justificaram o uso da fenomenologia explicando que o tema que pesquisaram, a agroecologia, não se apresenta de maneira objetiva a todos os envolvidos.

Cada um a percebe como um fenômeno de sua consciência e participa dela com motivações diferentes, de acordo com sua trajetória e experiência. Isso não impede que tenhamos similaridades e regularidades intersubjetivas. Essas condições de "intersubjetividade" são também fundamentais para o método fenomenológico (BAUER; MESQUiTA, 2008, p. 27).

Os autores utilizaram principalmente entrevistas semiestruturadas, com o objetivo de apreender um pouco a experiência de vida do agricultor na agricultura ecológica. Buscaram captar vivências tanto dos sujeitos pesquisados, quanto dos próprios pesquisadores, ressaltando que o ato de pesquisar foi também um ato de interpretação das "situações experienciadas de maneira subjetiva" (BAUER; MESQuita, 2008, p. 27). Com o trabalho, os pesquisadores disseram ter sido capazes de compreender que, apesar do importante papel que as organizações possuem em relação à mudança de uma realidade convencional para outra realidade ecológica, elas são as únicas mediadoras dessa transição, pois a experiência subjetiva e intersubjetiva do ator, do sujeito, é também um elemento crucial.

Ventura (2004), num ensaio bem lúdico, procura compreender a essência da fenomenologia, ou seja, compreender a própria fenomenologia de forma fenomenológica, como diz: "O propósito não foi o de entender e apresentar "tudo" sobre fenomenologia, mas aquilo que para a autora ficou de essencial 
no conceito" (VENTURA, 2004, p. I). Com base nessa experiência própria, procura então lançar seu olhar fenomenológico sobre o objeto que vai analisar, que é o conto infantil de Hans Christian Andersen: A roupa nova do imperador.

O conto fala de "dois artesões espertos que venderam ao Rei a ideia de que fariam para ele uma roupa muito bonita, mágica, que tinha o poder de ficar invisível aos olhos de quem não estivesse à altura do rei, ou de pessoas estúpidas. Encantado, o rei fez a encomenda aos tecelões e, de vez em quando, pedia a seus súditos diretos que averiguassem o trabalho. Eles não viam a roupa, mas por medo de serem considerados estúpidos ou incompetentes, diziam ao rei que a roupa estava ficando maravilhosa. Quando ficou pronta, os tecelões levaram a roupa ao rei, que não conseguia vê-la, mas que também a achou maravilhosa. No dia da procissão, o rei saiu com a roupa nova, mas todos na multidão admiravam sua elegância, até que uma criança observou e gritou: "o rei está nu".

Apoiada nessa experiência é que foi possível à autora lançar um olhar fenomenológico sobre seu objeto de estudo. Na perspectiva da fenomenologia, o conto é revelador: o que fez com que todos, inclusive o rei, acreditassem naqueles dois tecelões? Não parece tão "objetivo" o fato de o que falavam eram "enganação" e de que o rei de fato ficaria nu? Por meio da fenomenologia é possível pensar que não é bem assim. "Cada um vê a realidade de acordo com sua perspectiva, com seus valores e sua história de vida - sua experiência”, comenta Ventura (2004, p. 6).

Silva, Rebelo e Cunha (2003) abordaram o tema atividade gerencial. Procuraram compreender o processo de aprendizagem gerencial fundamentado na experiência de vida dos próprios gerentes, mais especificamente de dois gerentes de uma empresa do ramo de telecomunicações no Estado de Santa Catarina. Os autores desenvolveram a pesquisa com base no método da Fenomenologia Hermenêutica. Os sujeitos de pesquisa apresentam uma trajetória considerada audaciosa pelos pesquisadores, pois quando ainda jovens decidiram reunir economias que tinham e deixarem o papel de técnicos respeitados para ingressar na 
realidade da gestão e assumir papel de gerência. Para conduzir a pesquisa, realizaram primeiramente entrevista com o objetivo de reconstituir a história de vida dos gerentes pesquisados, por meio de relatos sobre espaços sociais diversos de suas vivências e convivências, como a família, a escola, os amigos, o trabalho e outros, levando-os a resgatar etapas e fatores que os levaram a se decidirem pela atividade de gerentes. Numa segunda parte da entrevista, os pesquisadores já buscaram elucidar detalhes da experiência dos sujeitos pesquisados na atividade de gerência. Na terceira parte, buscaram escutar os sujeitos a respeito da compreensão que tinham sobre a atividade gerencial.

Na medida em que foram obtendo os dados, os pesquisadores procuraram aplicar seu entendimento sobre a análise fenomenológica, buscando alcançar a essência do fenômeno. Uma das compreensões percebidas foi a de que o espaço social da família dos gerentes entrevistados teve influência determinante em suas escolhas para seguir a atividade gerencial.

A sólida estrutura familiar ajudou na aprendizagem gerencial, sobretudo nos momentos de sofrimento, de dificuldade e de dor. Nesse momento, lembrar que "meus pais sempre me deram a maior força para eu me formar e conseguir um negócio melhor para mim" auxiliava a superar as dificuldades inerentes à nova função (SILVA; REBELO; CUNHA, 2003, p. 8).

A pesquisa possui outros desdobramentos e resultados a respeito de fatores que influenciaram as escolhas dos sujeitos pesquisados, como a escola, a comunidade e a vida de empregado, mas as informações aqui apresentadas permitem uma noção razoável de como a conduziram e como aplicaram concepções fenomenológicas.

Grohmann (2005) também estudou a temática gerência por meio da aplicação da fenomenologia hermenêutica. Procurou compreendero impacto que a pós-graduação acarreta no processo de aprendizagem gerencial. A pesquisadora ouviu oito gerentes considerados não muito experientes ainda. A primeira parte das entrevistas se deu antes de iniciarem o curso de pósgraduação, e a segunda em seu término. Os principais aspectos na percepção dos sujeitos de pesquisa em relação à sua aprendizagem gerencial foram a 
ampliação de suas habilidades e valorização de outras, além da aquisição de novos conhecimentos voltados à atividade gerencial. As pessoas ouvidas não perceberam mudanças significativas em suas atitudes.

As entrevistas foram realizadas em três tempos, caracterizadas como entrevista fenomenológica em profundidade, técnica que combina entrevista com foco na história de vida e entrevista em profundidade. A autora foi uma das poucas, entre os estudos revistos para esta pesquisa, a salientar o conceito de epoché, utilizado no estudo: "foi necessário colocar em suspensão todo o conhecimento anteriormente construído", frisa Grohmann (2005, p. 3), e "todo este cuidado foi feito para que esta pesquisa não perdesse seu caráter qualitativo e interpretativo e que a visão de mundo do pesquisador não afetasse a visão de mundo dos entrevistados", enfatiza.

Anselmo e Garcez (2005, p. I) estudaram o tema capital de risco no Brasil. Como metodologia de pesquisa, utilizaram "técnicas de pesquisa documental e histórica utilizando metodologia de abordagem qualitativa de pesquisa do tipo fenomenológico". O objetivo foi avaliar o surgimento, a evolução histórica, as características e as perspectivas do mercado de capital de risco no Brasil. O estudo é feito com base em uma abordagem crítica dos estudos exploratórios e descritivos. A pergunta que norteou a pesquisa foi assim concebida pelos autores: "Como se deu o surgimento e a evolução histórica da indústria de capital de risco no Brasil, quais as características desta indústria e quais são suas perspectivas futuras"? (ANSELMO; GARCEZ, 2005, p. 8).

Os autores afirmaram que adotaram uma abordagem qualitativa do tipo fenomenológica, e o fenômeno estudado foi a indústria de capital de risco no Brasil, buscando compreendê-lo por meio do "círculo hermenêutico (compreensão - interpretação - nova interpretação)" (ANSELMO; GARCEZ, 2005, p. 9). Diferentemente da maioria das pesquisas baseadas na fenomenologia no campo dos estudos organizacionais, os pesquisadores não desenvolveram suas investigações com base na "perspectiva do sujeito", optando pela análise documental e bibliográfica. No estudo não ficou bem claro como os pesquisadores aplicaram a abordagem fenomenológica para a compreensão de informações contidas em documentos. 
Resende e Resende (2005) trataram da temática turismo. Mais especificamente, estudaram, por meio da abordagem fenomenológica, impactos positivos e negativos decorrentes das atividades turísticas baseadas na percepção dos atores sociais envolvidos. Buscaram obter também dessas pessoas soluções para os impactos negativos, a fim de que a qualidade e volume do turismo possam ser ampliados. Os principais impactos percebidos pelos sujeitos pesquisados estavam associados a fatores ambientais. Entre as principais soluções apontadas estão a de planejamento e normatização das atividades turísticas, além da necessidade de existência de maior cooperação entre os atores envolvidos com o turismo em Carrancas, no Estado de Minas Gerais.

As informações foram obtidas por meio de entrevistas individuais e em grupo, ouvindo representantes do poder público, empresários, proprietários rurais e a população local. As "análises" foram feitas após o término da etapa de obtenção de dados, que merecem algumas observações que serão feitas adiante, já que essa separação entre obtenção e análise não parece adequada a conceitos vinculados à fenomenologia. Entre os impactos positivos encontrados estão: econômicos, físico-ambientais, culturais e sociais. Em relação aos impactos negativos, os pesquisadores encontraram o incrível número de 59 impactos negativos no local, sendo que a maioria deles está relacionada a aspectos ambientais e sociais. O ponto alto da pesquisa foram, assim, os resultados significativos obtidos com base na percepção do quem é atingido por esses impactos, negativa ou positivamente. Os autores ressaltam os conflitos de interesse, dos quais transparecem contradições e inquietudes intrínsecas ao homem, conflitos difíceis de serem eliminados, avaliam. "Se os discursos conseguissem trocar estas ações por outras, como cooperação e a ajuda mútua, poder-se-ia chegar a concretizar um verdadeiro ecoturismo" (RESENDE; RESENDE, 2005, p. I4).

Rodrigues e Czarneski (2004) tiveram como objeto de estudo a ação empreendedora, para o que aplicaram conceitos da fenomenologia. Os autores ressaltaram que os altos índices de empreendedorismo no Brasil podem ser justificados mais pela necessidade de inserção no mercado de trabalho por parte das pessoas, do que propriamente pela oportunidade. Os 
resultados obtidos os levaram a crer que o desenvolvimento econômico não seria a causa do fenômeno da ação empreendedora, mas sim uma de suas consequências. Os autores desenvolveram uma pesquisa qualitativa, não experimental, frisam, pois não há seleção e tratamento de variáveis para que hipóteses sejam testadas. Assumiram que, apesar da existência de diferentes correntes ou abordagens do movimento filosófico da fenomenologia, optaram pela que consideraram mais adequada ao objetivo de pesquisa:

Colaborar com a percepção do processo sociocultural de formação da ação empreendedora pelo qual as pessoas organizam seus sonhos, atitudes ou necessidades de empreender, o que será buscado por meio da compreensão do fenômeno em estudo e de uma ação mediadora que pressupõe um plano de vida anterior ao plano de negócios (RODRIGUES; CZARNESKI, 2004, p. I).

Os pesquisadores foram dos poucos a mencionar limitações do conceito e do método utilizado, destacando principalmente a unilateralidade da análise, que se restringe ao trabalho isolado do pesquisador, inviabilizando o que chamam de "impossibilidade de precisão na coleta e classificação de dados" (RODRIGUES; CZARNESKI, 2004, p. 3), o que, diga-se, está numa dimensão ontológica e epistemológica oposta a raízes e concepções fenomenológicas. Como técnicas para obtenção de dados, foram utilizadas entrevista semiestruturadas por meio de questionários e contatos diretos com os entrevistados. Foi utilizada ainda a história de vida, colocando ênfase no contexto de vida dos sujeitos. Os resultados levaram os pesquisadores a pensar que a ação empreendedora não está desvinculada dos planos de vida das pessoas quando investem suas energias para empreender. Enfatizam, em relação à pesquisa e aos resultados, que não é o ato de explicar que ganha destaque em sua proposta, mas sim o de compreender o fenômeno estudado, no caso a ação empreendedora.

Queiroz (2004) desenvolve um trabalho bem peculiar ao combinar layout de escritório com conceitos fenomenológicos. O "fenômeno" objeto de seu estudo é o habitar. A autora tem como ponto de partida a observação de ambientes modificados, referenciando-se em elementos considerados teoricamente essenciais ao bem-estar das pessoas, no que refere ao espaço físico: a privacidade e a territorialidade. A pesquisa trata de três casos 
de mudança de layout, por meio de situações que revelam fenômenos decorrentes das interações entre usuários nesses espaços e elementos que o compõem. Os resultados alertam para a relevância dos elementos estudados, além de servirem de incentivo a sua aplicação na implantação de mudanças de layout nas organizações.

Coerente com a metodologia escolhida, Queiroz (2004, p. 6) desenvolve a pesquisa sobre "mudança de layout baseada na opinião do indivíduo", e protesta contra "o esquecimento da dimensão humana nas organizações". Segue em suas interpretações uma orientação fenomenológica predominantemente interpretativa, combinada com análise de conteúdo das informações obtidas em campo, privilegiando como técnicas de obtenção de dados a observação e a entrevista em profundidade. Os resultados revelaram que as opiniões dos usuários sobre as interações com o ambiente revelam fenômenos existenciais associados aos elementos que compõem os espaços estudados. A autora frisa ainda que as informações obtidas só foram possíveis por meio da observação direta dos fenômenos:

Outro método, que utilizasse exclusivamente questionários ou entrevistas formais, não identificaria situações como, por exemplo, o fato do contraste entre a ambiência interna e externa, resultando em insatisfação de ordem ambiental. Assim, concluímos a importância da utilização do método conjugado como instrumento de identificação de fenômenos (QUEIROZ, 2004, p. I4).

Ao final, a pesquisadora recomenda o aprofundamento de pesquisas em fenômenos específicos relacionados ao que estudou, como a identidade e a ambiência em nível subjetivo, defendendo a necessidade de que os valores nas organizações sejam repensados. "É preciso ver o indivíduo como parte imprescindível do todo. Vê-lo como tal é atitude de há muito necessária, mas ainda hoje inovadora" (QUeIrOz, 2004, p. I4).

Maisonnave e Rocha-Pinto (2008, p. I) realizam uma análise fenomenológica a respeito da percepção da inovação nos investimentos em pesquisa e desenvolvimento do setor elétrico brasileiro, sintetizando seu objetivo de pesquisa na seguinte questão: qual a percepção dos gestores sobre quanto a busca por inovação influencia o gerenciamento de 
investimentos em pesquisas e desenvolvimento no setor elétrico no Brasil? Em busca de respostas, os pesquisadores procuraram ouvir o ponto de vista de gestores de pesquisa e desenvolvimento das empresas estudadas. Ou seja, basearam-se no método fenomenológico para identificar essências do fenômeno com base nas experiências de vida dos sujeitos pesquisados. Os autores também fazem menção às dificuldades para aplicação do método de pesquisa escolhido, lembrando Moreira (2002) para ressaltarem a dificuldade existente na transposição de um método filosófico para um método de pesquisa.

Na pesquisa, utilizaram dois conceitos essenciais da fenomenologia: o da redução fenomenológica (epoché ou suspensão de julgamento) e o da redução eidética (a procura pela essência). Para obtenção de dados, optaram por entrevistas em profundidade, que foram gravadas e transcritas. Utilizando a análise fenomenológica, primeiro fizeram a descrição do fenômeno estudado tal como relatado nas entrevistas, para depois identificar e agrupar os temas em conjuntos de essências. Em suma, os pesquisadores buscaram seguir etapas sugeridas por Moreira (2002) para aplicação da análise fenomenológica.

"Amigos, amigos, negócios à parte! Com esse título criativo, Freitas et al. (2006, p. I) partem da acepção de trocas relacionais, "parte essencial ao entendimento da nova visão paradigmática do marketing", para desenvolverem um estudo que tem como objetivo "discutir a amizade desenvolvida em contextos comerciais entre clientes e provedores de serviços, explorando suas consequências de marketing". A pesquisa foi realizada com base na perspectiva fenomenológica, cujos dados foram obtidos por meio de entrevista em profundidade a clientes e profissionais de salão de beleza. Na interpretação de dados foi utilizada também a análise de conteúdo. Os resultados levaram os pesquisadores a sugerirem a abertura de mais espaço nos estudos organizacionais na área de marketing para discussão sobre o que é denominado amizade comercial, que envolve essencialmente intimidade, tempo de convívio e revelações pessoais. No grupo de clientes, acrescenta-se a estes a confiança no serviço 
do profissional, que pode ser usada na explicação do desenvolvimento e dissolução de uma relação de amizade (FREITAS ET AL., 2006, p. 9).

Os autores chegam a interpretações positivas a respeito da relação de amizade entre empregados e clientes, e que esses resultados poderiam sugerir que essas relações pudessem ser até mesmo encorajadas pelos gerentes de marketing. No entanto, "acreditam que tal sugestão parece não ser prudente, já que não se conhece a consequência de retirar o componente natural que aparenta existir na forma como se escolhe e se faz amigos" (FREITAS ET AL., 2006, p. Io).

É oportuno ainda apresentar o estudo feito por Rocha-Pinto; Freitas e Maisonnave (2008), que aborda implicações para os pesquisadores decorrentes da adoção de métodos interpretativistas no campo dos estudos organizacionais. Trata-se de um trabalho que serve como referência a estudiosos interessados pela fenomenologia e pelo método fenomenológico e sua aplicação em pesquisas sobre organizações. Além de conter informações bastantes e fundamentadas que ajudam a entender o método fenomenológico, o trabalho contribui para a compreensão do posicionamento da fenomenologia no paradigma interpretativista, com base nas ideias dos paradigmas sociológicos propostos por Burrell e Morgan (I979).

O estudo contempla também a grounded theory, informando sobre sua origem, seus pressupostos e sua aplicação nos estudos em Administração. Ao final, os autores mencionam um debate denso que está em pleno desenvolvimento no mundo das organizações, derivado de debates que seguiram aos feitos por Burrell e Morgam (1979), que pode ser assim resumido: Como cotejar duas ou várias visões diferentes de mundo a fim de que, ao final do processo, estejam suspensas as ideias preconcebidas a respeito do fenômeno sob investigação? (ROCHA-PINTO; FREITAS; MAISONNAVE, 2008, p. I5).

O panorama mostrado no Quadro 2 das abordagens fenomenológicas vistas neste artigo evidencia essa variedade significativa de fenômenos e temas estudados. Chama à atenção a combinação de uma abordagem 
fenomenológica com outro método de pesquisa, no caso a análise de conteúdo, utilizada em dois dos estudos. Mas em geral, os objetivos conservam em comum a busca dos pesquisadores por compreender o fenômeno estudado, baseado no ponto de vista dos sujeitos, na atitude que dá coerência à abordagem de pesquisa adotada ou assumida, associada à fenomenologia.

Quadro 2 Abordagens fenomenológicas adotadas ou assumidas nos artigos pesquisados

\begin{tabular}{|c|c|c|c|c|c|}
\hline Autoria & $\begin{array}{l}\text { Abordagem } \\
\text { adotada ou } \\
\text { assumida }\end{array}$ & $\begin{array}{l}\text { Fenômeno } \\
\text { pesquisado }\end{array}$ & $\begin{array}{l}\text { Técnicas de } \\
\text { Pesquisa }\end{array}$ & $\begin{array}{l}\text { Sujeitos } \\
\text { pesquisados }\end{array}$ & Objetivo \\
\hline $\begin{array}{l}\text { Bauer e } \\
\text { Mesquita } \\
(2008)\end{array}$ & $\begin{array}{l}\text { Abordagem } \\
\text { fenomenológica }\end{array}$ & $\begin{array}{l}\text { Relação entre } \\
\text { agricultor e } \\
\text { agroecologia }\end{array}$ & $\begin{array}{l}\text { Entrevistas } \\
\text { semiestruturadas }\end{array}$ & $\begin{array}{l}\text { Agricultores } \\
\text { ecológicos }\end{array}$ & $\begin{array}{l}\text { Compreender } \\
\text { o agricultor em } \\
\text { sua relação com } \\
\text { a agricultura eco- } \\
\text { lógica }\end{array}$ \\
\hline $\begin{array}{l}\text { Ventura } \\
(2004)\end{array}$ & $\begin{array}{l}\text { Olhar } \\
\text { fenomenológico }\end{array}$ & Fenomenologia & $\begin{array}{l}\text { Bibliográfica } \\
\text { (conto infantil) }\end{array}$ & -- & $\begin{array}{l}\text { Compreender o } \\
\text { conceito de feno- } \\
\text { menologia }\end{array}$ \\
\hline $\begin{array}{l}\text { Silva, Rebelo } \\
\text { e Cunha } \\
\text { (2003) }\end{array}$ & $\begin{array}{l}\text { Fenomenologia } \\
\text { Hermenêutica }\end{array}$ & $\begin{array}{l}\text { Aprendizagem } \\
\text { gerencial }\end{array}$ & $\begin{array}{l}\text { Entrevista e } \\
\text { conversação }\end{array}$ & $\begin{array}{l}\text { Gerentes } \\
\text { do setor de } \\
\text { telecomunicações }\end{array}$ & $\begin{array}{l}\text { Compreender } \\
\text { o processo de } \\
\text { aprendizagem } \\
\text { gerencial }\end{array}$ \\
\hline $\begin{array}{l}\text { Grohmann } \\
\text { (2005) }\end{array}$ & $\begin{array}{l}\text { Fenomenologia } \\
\text { Hermenêutica }\end{array}$ & $\begin{array}{l}\text { Aprendizagem } \\
\text { gerencial }\end{array}$ & $\begin{array}{l}\text { Entrevista } \\
\text { com foco na } \\
\text { história de vida } \\
\text { e entrevista em } \\
\text { profundidade }\end{array}$ & $\begin{array}{l}\text { Gerentes de } \\
\text { empresas }\end{array}$ & $\begin{array}{l}\text { Entender o } \\
\text { impacto da } \\
\text { educação pós- } \\
\text {-graduada no } \\
\text { processo de } \\
\text { aprendizagem } \\
\text { gerencial }\end{array}$ \\
\hline $\begin{array}{l}\text { Anselmo } \\
\text { e Garcez } \\
(2005)\end{array}$ & $\begin{array}{l}\text { Abordagem } \\
\text { qualitativa de } \\
\text { pesquisa do tipo } \\
\text { fenomenológico }\end{array}$ & Capital de risco & $\begin{array}{l}\text { Pesquisa } \\
\text { documental e } \\
\text { histórica }\end{array}$ & -- & $\begin{array}{l}\text { Avaliar o a evolu- } \\
\text { ção histórica, as } \\
\text { características e } \\
\text { as perspectivas } \\
\text { do mercado de } \\
\text { capital de risco } \\
\text { no Brasil }\end{array}$ \\
\hline $\begin{array}{l}\text { Resende e } \\
\text { Resende } \\
(2005)\end{array}$ & $\begin{array}{l}\text { Abordagem } \\
\text { fenomenológica }\end{array}$ & Turismo & $\begin{array}{l}\text { Entrevistas } \\
\text { individuais e em } \\
\text { grupo }\end{array}$ & $\begin{array}{l}\text { Representantes } \\
\text { do poder público, } \\
\text { empresários, prop. } \\
\text { rurais e população } \\
\text { local }\end{array}$ & $\begin{array}{l}\text { Analisar impac- } \\
\text { tos positivos e } \\
\text { negativos decor- } \\
\text { rentes de ativida- } \\
\text { des turísticas em } \\
\text { Carrancas, MG }\end{array}$ \\
\hline
\end{tabular}




\begin{tabular}{|c|c|c|c|c|c|}
\hline Autoria & $\begin{array}{l}\text { Abordagem } \\
\text { adotada ou } \\
\text { assumida }\end{array}$ & $\begin{array}{l}\text { Fenômeno } \\
\text { pesquisado }\end{array}$ & $\begin{array}{l}\text { Técnicas de } \\
\text { Pesquisa }\end{array}$ & $\begin{array}{l}\text { Sujeitos } \\
\text { pesquisados }\end{array}$ & Objetivo \\
\hline $\begin{array}{l}\text { Rodrigues } \\
\text { e Czarneski } \\
\text { (2004) }\end{array}$ & $\begin{array}{l}\text { Aplicação de } \\
\text { conceitos da } \\
\text { fenomenologia }\end{array}$ & $\begin{array}{l}\text { Ação } \\
\text { empreendedora }\end{array}$ & $\begin{array}{l}\text { Entrevista } \\
\text { semiestruturada } \\
\text { combinada com } \\
\text { história de vida }\end{array}$ & $\begin{array}{l}\text { Pessoas } \\
\text { empreendedoras }\end{array}$ & $\begin{array}{l}\text { Compreender } \\
\text { a relação entre } \\
\text { ação empreen- } \\
\text { d e d o r a e } \\
\text { empreendedor }\end{array}$ \\
\hline $\begin{array}{l}\text { Queiroz } \\
(2004)\end{array}$ & $\begin{array}{l}\text { Orientação } \\
\text { fenomenológica } \\
\text { combinada } \\
\text { com análise de } \\
\text { conteúdo }\end{array}$ & $\begin{array}{l}\text { Lay-out em } \\
\text { organizações }\end{array}$ & $\begin{array}{l}\text { Observação e } \\
\text { a entrevista em } \\
\text { profundidade }\end{array}$ & $\begin{array}{l}\text { Funcionários de } \\
\text { escritórios }\end{array}$ & $\begin{array}{l}\text { Compreender } \\
\text { a relação entre } \\
\text { ambiente orga- } \\
\text { nizacional modi- } \\
\text { ficado e satisfa- } \\
\text { ção pessoal }\end{array}$ \\
\hline $\begin{array}{l}\text { Maisonnave } \\
\text { e Rocha- } \\
\text { Pinto (2008) }\end{array}$ & $\begin{array}{l}\text { Análise } \\
\text { fenomenológica }\end{array}$ & $\begin{array}{l}\text { Inovação setor } \\
\text { elétrico }\end{array}$ & $\begin{array}{l}\text { Entrevistas em } \\
\text { profundidade }\end{array}$ & $\begin{array}{l}\text { Gestores de } \\
\text { empresas no setor } \\
\text { elétrico no Brasil }\end{array}$ & $\begin{array}{l}\text { Entender a } \\
\text { influência da } \\
\text { busca por ino- } \\
\text { vação no geren- } \\
\text { ciamento de } \\
\text { investimentos } \\
\text { em pesquisas }\end{array}$ \\
\hline $\begin{array}{l}\text { Freitas et al. } \\
\text { (2006) }\end{array}$ & $\begin{array}{l}\text { Perspectiva } \\
\text { fenomenológica } \\
\text { combinada } \\
\text { com análise de } \\
\text { conteúdo }\end{array}$ & $\begin{array}{l}\text { Relações de } \\
\text { amizade entre } \\
\text { empregados e } \\
\text { clientes }\end{array}$ & $\begin{array}{l}\text { Entrevista em } \\
\text { profundidade }\end{array}$ & $\begin{array}{l}\text { Clientes e } \\
\text { profissionais de } \\
\text { salão de beleza }\end{array}$ & $\begin{array}{l}\text { Entender a } \\
\text { amizade em } \\
\text { contextos } \\
\text { comerciais } \\
\text { entre clientes e } \\
\text { provedores de } \\
\text { serviços }\end{array}$ \\
\hline
\end{tabular}

Deve-se ressaltar que mesmo em pesquisas em que não foram estudados temas fundamentados na perspectiva do sujeito ou de sua experiência de vida, a abordagem de pesquisa baseada na fenomenologia se mostrou robusta. Destaque-se o ensaio de Ventura (2004), no qual mostra de forma lúdica e inteligente o potencial de utilização da fenomenologia como recurso teórico e metodológico nas pesquisas organizacionais.

Analogamente ao conto unidade de análise em Ventura (2004), quantas são as situações no ambiente organizacional envolvendo, por exemplo, disputa por poder e por cargos, relações mal ou bem resolvidas entre dirigentes ou dirigidos, dominação, entre outras, não poderiam ser estudadas com o auxílio da fenomenologia? A autora ressalta o ponto de singularidade, ruptura, da história de vida de cada pessoa, que a leva a enxergar a roupa nova do rei. Mas, com base no grito da criança, ou no grito de um cientista 
interessado em romper com as regras e padrões estabelecidos, é que se pode se mudar algo, diz Ventura (2004).

Nesse conto, tomado como parábola metafórica, há no seu discurso uma intencionalidade deliberada dos artesãos, não em expor o Rei ao ridículo, mas de se apropriar de riqueza de forma ilícita. Assim, em analogia, poderse-ia dizer de pesquisadores que, de forma deliberada, violam dados de pesquisa. Mas se ignorância é apenas dolo (quando descoberto) e, na gíria popular, se aprende mais com erros que com acertos, não se desmerece o trabalho do pesquisador que, de forma "ignorada", o apresenta ao mundo do "mainstrean" e o torna público e operacional na vida das pessoas quando de sua comunicação. Dessa fábula simples, depreende-se a importância da abordagem fenomenológica. Um recorte isolado do contexto, excluindo os artesãos do episódio fático, poder-se-ia levar a uma interpretação de que o Rei era, não ingênuo e pudico, como requer o texto, mas sim um despudorado exibicionista.

Enfim, oque os artigos analisados parecem mostrar, fenomenologicamente dizendo, é que a fenomenologia tem potencial metodológico significativo para o estudo dos mais variados problemas (fenômenos) no campo dos estudos organizacionais. Como foi observado, as temáticas pelas quais têm passado são vastas e variadas. Apenas para citar algumas, revisitadas no decorrer desta pesquisa, serviram como temas de estudo a setores ou atividades como o de turismo, capital de risco, energia, cadeias de suprimentos, agronegócio, agroecologia, entre outros. No tocante a assuntos mais associados à subjetividade, foram contemplados, por exemplo, estudos sobre aprendizagem gerencial, identidade nas organizações, inovação, impacto do lay-out de escritórios, confiança nas relações, políticas de gestão de pessoas, cultura organizacional, mudança organizacional, mudança de cultura, regionalidade, entre outros. 


\section{CONSIDERAÇÕES FINAIS OU O QUE, FENOMENOLOGICAMENTE INTERPRETANDO, OS ARTIGOS REVISITADOS PARECEM MOSTRAR}

O objetivo deste artigo foi apresentar um entendimento de como o método fenomenológico vem sendo utilizado ou que abordagens fenomenológicas vêm sendo adotadas ou assumidas em pesquisas no campo dos estudos organizacionais. É possível observar que os temas abordados são diversificados, mas a fonte de dados e de informações baseiase preponderante no sujeito, ou seja, as informações são obtidas com base no ponto de vista ou na perspectiva do indivíduo envolvido no problema estudado. Porém, existem alguns estudos que investigam determinados fenômenos fundamentados em outras fontes de dados, como documentos, bibliografias, relatórios, observação etc., revelando ainda mais o potencial da utilização da fenomenologia ou de seus conceitos.

Outra consideração a ser feita diz respeito à forma com que diferentes pesquisadores conduzem as partes de obtenção e interpretação de dados. Mesmo entre os que realizam estudos baseados na "perspectiva do sujeito", que são a maioria, alguns preferem num primeiro momento obter todos os dados, para somente depois se debruçarem sobre eles e interpretá-los. Se consideradas as essencialidades dos conceitos envolvidos na fenomenologia ou no método fenomenológico, como os de fenômeno e essência, por exemplo, é razoável pensar que mais prudente seria realizar os dois momentos sincronamente, ou seja, conduzir a interpretação na medida em que os dados forem sendo obtidos, para não se correr o risco de perder elementos, por assim dizer, essenciais do fenômeno observado. Ou seja, separar o momento de obtenção de dados do momento de sua interpretação pode não estar condizente com a acepção de método fenomenológico de pesquisa, aspecto que deve ser levado em conta por pesquisadores que queiram utilizar o método fenomenológico ou abordagens dele derivadas.

Outro ponto a destacar diz respeito às variadas formas de compreensão e aplicação da fenomenologia ou do método fenomenológico. É possível observar uma gama significativa de autores referenciados nos trabalhos, seguidores dos passos de Husserl, que também construíram ou tentaram 
construir caminhos interpretativos próprios. Por sua vez, os próprios estudiosos das organizações, que buscam base para suas pesquisas em teorias derivadas do pensamento de Husserl, parecem dar a elas ao menos uma "pincelada" de interpretações próprias. Mas, pensando que o próprio Husserl admitia que suas ideias eram inacabadas, que ele próprio se achava um iniciante em filosofia, observa-se que que essa diversidade de pensamento e de aplicação da fenomenologia no campo de estudos organizacionais guarda consonância com essa trajetória "turbulenta". Ademais, são muitos os estudiosos clássicos no campo filosófico que admitem que a fenomenologia se constitua ainda um campo de estudo repleto de dúvidas, tendo inclusive alguns conceitos próprios ainda "mal resolvidos". De fato, uma trajetória que pode ser considerada ainda embrionária, mas que se já se mostra promissora à pesquisa social e em Administração.

Nessa sua trajetória, a fenomenologia nasce como filosofia, mas Zilles (1996) apresenta que sua pretensão é ser a ciência das essências, e não dos fatos. Nisso depreende-se que a fenomenologia é includente no seu jeito de apreender o conhecimento, ao tratar os geradores do fenômeno, o contexto e os elementos estruturantes em conjunto e de maneira inter-relacionada. Significa que a apreensão do conhecimento nessa abordagem pode recorrer a cortes, mas não se podem dissociar as relações de toda ordem, sejam anárquicas, "sense making", sejam nomológicas.

No decorrer do tempo, especialmente nos últimos anos, a fenomenologia tornou-se cada vez mais utilizada como abordagem teórica e metodológica nas ciências sociais, e se destaca também nos estudos organizacionais. Há que se entender que a fenomenologia se posiciona em uma dimensão abstracional mais de conceito de abordagem do que de processos (e esses replicáveis). Ou seja, não se deve separar conceito de abordagem e de processo explicativo. Esse é um duelo abstracional que a fenomenologia deve enfrentar. Se ela ficar apenas no conceito de abordagem, sem se apropriar do processo, corre o risco de perder campo. Assim, afirmar a existência de um método de pesquisa fenomenológico, de fato, é ainda muito cedo. 
Esta pesquisa parece ter contribuído também para reforçar a compreensão que Moreira (2002; 2002a) tem a respeito da ainda pouca utilização da fenomenologia ou do método fenomenológico nos estudos organizacionais no Brasil. A dificuldade encontrada para a aplicação dos conceitos fenomenológicos pode decorrer, principalmente, de sua pouca utilização, mas este estudo ajudou a mostrar que cada vez mais estudiosos estão entrando nesse complexo e instigante universo, principalmente aqueles interessados na construção de conhecimento baseado na experiência de vida das pessoas. 


\section{REFERENNCIAS}

ANSELMO, J.; GARCEZ, M. O Panorama Brasileiro do Capital de Risco:

Características, Evolução e Perspectivas. In: EnANPAD, 29, 2005, Curitiba. Anais...

Curitiba: ANPAD, 2005.

BACON, F. Novum organum ou verdadeiras indicações acerca da interpretação da natureza. São Paulo, Nova Cultural, 1988.

BAUER, M. A. L.; MESQUITA, Z. Organizações sociais e agroecologia: construção de identidades e transformações sociais. Revista de Administração de Empresas, v. 48, n. 3, p. 23-34, 2008.

BERGER, P. L., LUCKMANN, T. A construção social da realidade: Tratado de sociologia do conhecimento. 23.ed. Vozes, Petrópolis, 2003.

BURRELL, M.; MORGAN, G. Sociological paradigms and organizational analisys. London: Heinemann, 1979.

DARTIGUES, A. O que é a fenomenologia? São Paulo: Moraes, 1992.

DURKHEIM, E. Educação e sociologia. São Paulo: Melhoramentos, 1972.

FORGHIERI, Y. C. (Org.). Fenomenologia e Psicologia. São Paulo: Cortez : Autores Associados, 1984.

FREITAS, A. A. F. de; MAZZA, A. C. A.; PINHEIRO, K. B. P.; PERDOMO, J. M. L. Amigos, Amigos, Negócios à Parte! Reflexões Acerca da Amizade Comercial. In: EnANPAD, 30, 2006, Salvador.. Anais... Salvador.: ANPAD, 2006.

GIL, A. C. Como elaborar projetos de pesquisa. 4.ed. São Paulo: Atlas, 2002.

GIORGI, A. Phenomenology and psychological research. Pittsburg: Duqueme University, Press, 1985.

GROHMANN, M. Z. Influências de um Curso de Pós-Graduação "Lato Sensu” na Aprendizagem Gerencial. In: EnANPAD, 29, 2005, Curitiba. Anais... Curitiba: ANPAD, 2005.

HUSSERL, E. A ideia da fenomenologia. Lisboa: Edições 70, 2001.

HUSSERL, E. Investigaciones lógicas. Madri: Castilha, 1967.

LYOTARD, J. F. A fenomenologia. São Paulo: Difusão, 1967.

MAISONNAVE, P. R.; ROCHA-PINTO, S. R. da. Uma Análise Fenomenológica a respeito da percepção da Inovação nos Investimentos de Pesquisa e Desenvolvimento do Setor Elétrico Brasileiro. In: EnANPAD, 32, 2008, Rio de Janeiro. Anais... Rio de Janeiro: ANPAD, 2008.

MERLEAU-PONTY, M. Fenomenologia da Percepção. São Paulo: Martins Fontes, 1999. MORAN, J. M. Ensino e aprendizagem: inovadores com tecnologias audiovisuais e telemáticas. In: MORAN, J.M.; MASETTO, M.; BEHRENS, M.A. Novas tecnologias e 
mediação pedagógica. Campinas: Papirus, 2000.

MOREIRA, D. A. O Método Fenomenológico na Pesquisa. São Paulo: Thompson Pioneira, 2002.

MOREIRA, D. A. Pesquisa em Administração: Origens, usos e variantes do método fenomenológico. In: EnANPAD, 26, 2002, Salvador.. Anais... Salvador.: ANPAD, 2002a.

MOUSTAKAS, C. Phenomenological Research Methods. Thousand Oaks: Sage Publications, 1994.

QUEIROZ, A. A. F. S. L. de. Influências do Layout de Escritórios: privacidade e territorialidade na ótica do usuário de espaços modificados. In: EnANPAD, 28, 2004, Curitiba. Anais... Curitiba: ANPAD, 2004.

RESENDE, C. F.; RESENDE, D.C. de. Impactos do Turismo: Uma Análise Sob a Ótica da População Receptora. In: EnANPAD, 29, 2005, Curitiba. Anais... Curitiba: ANPAD, 2005.

RIBEIRO JR, J. Fenomenologia. São Paulo: PANCAST, 1991.

ROCHA-PINTO, S. R. da; FREITAS, A. S. de; MAISONNAVE, P. R. Métodos interpretativistas em Administração: as implicações para o(a) pesquisador(a). In: EnANPAD, 32, 2008, Rio de Janeiro. Anais... Rio de Janeiro: ANPAD, 2008.

RODRIGUES, P. H. M. R.; CZARNESKI, F. R. A Mediação Sociocultural na Ação Empreendedora: Por um Plano de Vida que Anteceda o Plano de Negócios. In: EnANPAD, 28, 2004, Curitiba. Anais... Curitiba: ANPAD, 2004.

SILVA, A. B. da S.; REBELO, L. M. B.; CUNHA, C. J. C. de A. Aprendizagem de gerentes: a perspectiva da experiência vivida. In: EnANPAD, 27, 2003, Atibaia/SP. Anais... Atibaia/SP: ANPAD, 2003.

SILVEIRA, R. Z. ; FISCHER, C. ; OLIVIER, M. A Fenomenologia como Método de Pesquisa: uma Análise a Partir dos Trabalhos Publicados nos Principais Eventos e Revistas Nacionais em Administração - 1997 a 2008. In: EnANPAD, 34, 2010, São Paulo. Anais... São Paulo: ANPAD, 2010.

VENTURA, E. C. F. O rei está nu? Pensando fenomenologicamente A roupa nova do imperador. Cadernos EBAPE. Rio de janeiro, v. II, n. 1. Mar, 2004.

ZILLES, U. Filosofia da Religião. 2.ed. São Paulo: Paulus, 1996. 


\section{DADOS DOS AUTORES}

ROGÉRIO ZANON DA SILVEIRA^ rsilveira@sefaz.es.gov.br

Mestre em Administração pela UFES-PPGADM

Doutorando em Administração pela UFMG-CEPEAD

Instituição de vinculação: Universidade Federal de Minas Gerais - CEPEAD

Belo Horizonte/MG - Brasil

Áreas de interesse em pesquisa: Democracia,

participação e subjetividade em organizações e instituições.

*Av. Jerônimo Monteiro, 96, $7^{\circ}$ andar Centro Vitória/ES 29010-002

ANA CAROLINA GUERRA ana.guerra@unifal-mg.edu.br

Mestre em Administração pela UFLA

Doutoranda em Administração pela UFMG-CEPEAD

Instituição de vinculação: Universidade Federal de Alfenas

Alfenas/MG - Brasil

Àreas de interesse em pesquisa: Trabalho, Gestão de Pessoas, Economia Solidária, Políticas Públicas, Métodos e Técnicas de Pesquisa.

CARLOS ALBERTO GONÇALVES carlos@face.ufmg.br

Doutor em Administração pela USP

Instituição de vinculação: Universidade Federal de Minas Gerais - CEPEAD

Belo Horizonte/MG - Brasil

Áreas de interesse em pesquisa: Estratégia Organizacional,

Gestão e Processos para Inovação, Empreendedorismo,

Métodos e Técnicas de Pesquisa. 